\title{
OS FAZERES DE BEBÊS E SUAS PROFESSORAS NA ORGANIZAÇÃO PEDAGÓGICA CENTRADA NA CRIANÇA
}

Tacyana Karla Gomes Ramos (UFS)*

\begin{abstract}
RESUMO
O presente estudo busca captar o ponto de vista de bebês sobre a organização das práticas educativas, explorando suas possibilidades expressivas não verbais, em situações cotidianas da Educação Infantil. Participaram da pesquisa duas professoras, seis Auxiliares de Desenvolvimento Infantil e 31 crianças de ambos os sexos, com idades entre 08 e 16 meses, integrantes de dois Centros Municipais de Educação Infantil da cidade do Recife-PE. Foram realizadas 38 sessões de filmagem durante três meses. Os dados foram produzidos por meio da análise microgenética, em que cada sessão foi observada atentamente a fim de serem recortados e descritos episódios interacionais. Olhar para o bebê no contexto da Educação Infantil e ouvi-lo em seus interesses viabilizou a captura e a compreensão de seu ponto de vista como elemento que balizou a construção de um trabalho pedagógico a partir das competências sociocomunicativas que seu comportamento interativo pôde desvelar em parceria com suas professoras.
\end{abstract}

Palavras-chave: Bebês. Práticas pedagógicas. Educação infantil. Relações entre pares.

\section{ABSTRACT \\ CHILDREN'S DOINGS AND THEIR TEACHERS IN THE CHILD-CENTERED PEDAGOGICAL PRACTICES}

The purpose of this study is to understand children's perspective on the planning of educational practices, exploring their expressive nonverbal communication, in everyday situations in the context of the Early Childhood Education (ECE). The participants of this study were: two teachers, six teacher assistants, and 31 children of both sexes, aged 8-16 months, members of two municipal centers for ECE, in Recife, PE, Brazil. During three months, 38 filming sessions were recorded. A microgenetic analysis was conducted to generate the data. All sessions were carefully analyzed in order to be cut out and described in interactive episodes. Looking at the children's perspective in the context of ECE and understanding their point of view, led us to the development of a pedagogical work based on the socio-communicative competence that their interactive behavior could unveil along with their teachers.

Keywords: Children. Pedagogical practices. Early childhood education. Peer relations.

* Mestrado e Doutorado em Educação pela Universidade Federal de Pernambuco (UFPE). Professora Adjunta IV do curso de Pedagogia da Universidade Federal de Sergipe (UFS) e docente do Programa de Pós-Graduação em Educação (PPGED/UFS). E-mail: tacyanaramos@gmail.com 


\section{RESUMEN}

\section{LAS ACTIVIDADES ENTRE PROFESORAS Y BEBÉS EN LA ORGANIZACIÓN PEDAGÓGICA CENTRADA EN EL NIÑO}

Este estudio busca captar el punto de vista de los bebés en la organización de las prácticas educativas, explorando sus posibilidades expresivas no verbales en situaciones cotidianas de la Educación Infantil. En la investigación participaron dos profesoras, seis auxiliares de desarrollo infantil y 31 niños de ambos sexos, con edades entre 08 y 16 meses, integrantes de dos Centros Municipales de Educación Infantil de la ciudad de Recife, PE, Brasil. Los datos fueron recogidos por medio del análisis microgenético, en que cada sesión fue observada atentamente a fin de ser recortados y descritos episodios interactivos. Se realizaron 38 sesiones de filmación durante tres meses. Mirar al bebé en el contexto de la Educación Infantil y oírlo en sus intereses posibilitó la captura y la comprensión de su punto de vista como elemento que permite el desarrollo de un trabajo pedagógico a partir de las competencias sociocomunicativas que el comportamiento interactivo del bebé pudo manifestar en compañía de sus profesoras.

Palabras clave: Bebés. Prácticas pedagógicas. Educación infantil. Relaciones entre pares.

\section{Introdução'}

A ideia de criança protagonista de ações, competente socialmente, dona de uma curiosidade investigativa original que lhe permite aproveitar todas as situações interativas e exploratórias das quais participa para produzir conhecimentos, descortina os principais elementos da presente investigação, que busca capturar o ponto de vista dos bebês como elemento balizador da organização das práticas educativas, explorando suas possibilidades expressivas não verbais, em situações cotidianas da Educação Infantil organizadas por suas professoras, tomando como pressupostos as ideias de que eles têm o que dizer, ou seja, possuem recursos sociocomunicativos para demonstrar suas intenções, interesses e necessidades, partilhando significados através dos meios funcionais de que dispõem, mesmo na ausência da fala articulada (RAMOS, 2010).

Tendo como principais interlocutores, neste projeto, os estudos sobre a criança com base na perspectiva de escuta às suas necessidades, aos seus desejos e suas inquietações (CRUZ, 2008),

1 Estudo realizado com aprovação do Comitê de Ética em Pesquisa da Universidade Federal de Pernambuco (Protocolo CAAE $n^{\circ}$ 0178.0.172.000-08) e também com consentimento das professoras e dos responsáveis pelas crianças integrantes da pesquisa. o estudo busca romper com a lógica que coloca o bebê em uma posição socialmente inferior aos adultos, uma vez que, durante vários séculos, a criança teve a sua presença social apagada por concepções que a colocavam numa posição de incompetência, subordinação e preparação para a vida adulta (CAMAIONI, 1980; CARVALHO; BERALDO, 1989).

Ao longo da história, a criança não é vista em termos das relações sociais que estabelece. Dessa forma, predominavam as discussões acerca da infância e da criança diante de uma perspectiva adultocentrada, negando à criança falar sobre si mesma, suas expectativas, seus desejos, interesses e formas de ver o mundo, ou ofuscando o reconhecimento de suas possibilidades.

O próprio significado etimológico da palavra infante (aquele que não fala) circunscreve significados construídos historicamente que silenciam suas ideias (CRUZ, 2008). O que sabemos sobre a criança, na maioria das pesquisas, é o que nos foi contado pelos adultos e não pela própria criança (CAMPOS, 2008; ROCHA, 2008).

Atualmente, entretanto, vários estudos apontam para uma direção que permite a inversão do olhar que, ao enxergar a criança como construtora ativa 
e socialmente competente, dá-lhe vez e voz no cenário sócio-histórico.

Nessa trilha de proposições, as emergentes descobertas sobre como a criança aprende e se desenvolve vem fomentando na pesquisa o desejo de conhecer suas inúmeras peculiaridades, dando-lhe visibilidade pela ótica de sua posição protagonista de enredos construídos com os eventos de seu tempo (COHN, 2005; CORSARO, 2005) e lhe conferindo um status de participante criativo na construção de seu espaço social (KUHLMANN JUNIOR, 2007).

$\mathrm{Na}$ busca de uma ruptura com a lógica adultocêntrica, estudiosos defendem a perspectiva de investigações que pensem nas crianças, nos seus contextos, nos modos como negociam e interagem em grupos, ou seja, o que se passa entre elas, procurando os significados que constroem (DELGADO; MÜLLER, 2005) por meio da escuta de suas diversificadas formas de expressão (EDWARDS; GANDINI; FORMAN, 1999). Nas palavras de Cruz (2008, p. 13): “[...] buscar formas de ouvir as crianças, explorando as suas múltiplas linguagens, tem como pressupostos a crença de que elas têm o que dizer e o desejo de conhecer o ponto de vista delas". Corroboram com essa perspectiva as ideias de Sarmento (2008), ao defender que a infância precisa ser estudada considerando-se a "voz" das crianças, o que permitirá descortinar outra realidade social e cultural, emergente das interpretações infantis.

Congruentes com essa perspectiva e reconhecendo os bebês como seres sociais, capazes de interação desde o nascimento, considera-se que seus processos relacionais se dão de forma ativa, histórica e cultural. Portanto, neste trabalho, nos reportaremos às contribuições da Psicologia, que reconhece as competências sociocomunicativas da criança e estuda seus processos comunicativos não verbais. Reconhecemos que a criança possui inclinação para investir no seu próprio desenvolvimento, diferentemente de ser incompleto e em processo de treinamento para a vida adulta (CARVALHO; PEDROSA, 2002; RIBEIRO; BUSSAB; OTTA, 2004), sendo capaz de participar de relações sociais e interativas com os recursos de que dispõe, desde bebê (WALLON, 1971).
Seguindo nessa esfera de argumentação que reconhece a potência social da criança, os estudos na área da Sociologia da Infância têm investido em dar visibilidade à infância como construção social e à criança como protagonista social, sujeito capaz de aprovar, propor e resistir diante das situações e ideias para elas reservadas (SOUZA, 2007).

Nessa esfera de argumentação, pesquisadores (MARTINS FILHO, 2005; MARTINS FILHO et al, 2006; MONTANDON, 2005; RAMOS, 2010) têm analisado as interações e manifestações infantis frente ao proposto pelos adultos no interior dos ambientes educacionais, na medida em que os resultados dos estudos constatam a possibilidade de que as crianças podem atuar como informantes das especificidades de sua infância e de seus interesses.

Ampliando o debate, Montandon (2005, p. 485) reivindica para as crianças o lugar de ator social na Educação Infantil quando afirma que "importa analisar não apenas o que os educadores fazem com as crianças, como também o que estas fazem com o que se faz com elas".

Oliveira-Formosinho, Kishimoto e Pinazza (2007) também fortalecem nosso argumento ao defenderem a ideia de a criança ter um espaço de participação no fazer pedagógico baseada num processo dialógico de escuta e de negociações entre a intencionalidade conhecida para o ato educativo e a sua codefinição pelos sujeitos aprendizes. Segundo essas autoras, esse modo de pensar a ação pedagógica contribui para reduzir a distância entre as propostas dos adultos e as iniciativas das crianças, promovendo interfaces entre seus interesses, necessidades e ideias na configuração didática.

Tais ideias convocam um olhar atento e curioso para a criança, perpassado pela construção, por parte do(a) professor(a), de uma sensibilidade em relação à criança, tendo como perspectiva uma atitude investigativa em que o adulto profissional busca entender a ação infantil, perscrutando seus mecanismos sociais, afetivos e mentais. E mais: realça uma sensibilidade que é propalada pela observação atenta do comportamento interativo da criança aliada à investigação da própria prática que desenvolve (RAMOS, 2010). Simultaneamente a um refinamento no olhar sobre o comportamento 
interativo da criança, estabelecem-se possibilidades de organização didática diante da especificidade do sujeito infantil que emerge deste exercício de aprender a conhecê-lo (JABLON; DOMBRO; DICHTELMILLER, 2009).

Nessa perspectiva, a Educação Infantil torna-se um espaço fecundo para se conhecer a desenvoltura social da criança, para se pensar em "muitas crianças e diversas infâncias" (MOSS, 2005, p. 237), abrindo espaço para a construção cotidiana da prática educativa que fomente no(a) professor(a) uma postura contínua de avaliação do trabalho que desenvolve a partir dos indicadores das crianças.

Congruentes com essa perspectiva, Ades (2009) inspira o/a professor(a) a ter uma postura de proximidade com a criança que rompe com a visão autoritária, que não enxerga a desenvoltura social infantil. Através de seu comportamento de pesquisador, $\mathrm{o}$ autor inspira $\mathrm{o}$ adulto profissional a adotar uma posição de parceiro, capaz de dialogar, estabelecer vínculos de amizade e transportar-se para as perspectivas da criança como forma de compreendê-la.

Vale ressaltar que não estamos defendendo uma postura passiva ou espontaneísta quanto à intencionalidade pedagógica do(a) professor(a). Ao contrário, concordamos que a função docente supõe um constante olhar crítico sobre o trabalho pedagógico e a consequente renovação dos saberes (PIMENTA, 1999; TARDIF, 2002), mas que também possa abrir perspectivas para o imprevisto e não a improvisação (FARIA, 2007). Isso implica na possibilidade docente de construção de significados com as crianças e sua infância numa determinada instituição, marcada por uma organização pedagógica planejada cotidianamente e avaliada sistematicamente (TRISTÃO, 2004). E mais: implica a compreensão da indissociabilidade do cuidar/educar a criança (BRASIL, 2009); o planejamento de atividades diversificadas, centradas nos interesses dos diferentes agrupamentos etários e nas singularidades infantis (KUHLMANN JUNIOR, 2007); prevê a organização de ambientes que promovam aprendizagens através de diferentes experiências (HORN, 2004); busca ouvir, ver, deixar-se inspirar e aprender com o que as crianças dizem e fazem (KRAMER, 2003; MOSS, 2005); provoca opor- tunidades para que a criança se expresse por meio de diferentes linguagens (EDWARDS; GANDINI; FORMAN, 1999).

Nesse sentido, a criança passa a ser entendida como sujeito não compartimentalizado e como interlocutora dinâmica no seu relacionamento com o mundo: empenhada num processo de contínua interação com seus pares, com os adultos, com a cultura, estando disponível para ser vista em suas potencialidades, inserida no centro do planejamento pedagógico e vista como um ser capaz de participar de seu processo educativo com os conhecimentos e recursos de que dispõe, desde bebê.

Diante do exposto, pensar a participação dos bebês na organização deste estudo implicou tanto no reconhecimento de suas capacidades, quanto instigou a busca de procedimentos metodológicos que pudessem capturar as sutilezas e as características de sua competência social, reveladas em seu comportamento interativo com parceiros de idade e adultos profissionais nas práticas cotidianas da Educação Infantil, conforme discutiremos nos dados empíricos apreendidos.

O presente estudo pretende analisar as interações de crianças e educadoras em situações cotidianas da Educação Infantil na busca de captar o ponto de vista de bebês sobre a organização das práticas educativas que lhes são ofertadas, explorando as possibilidades expressivas não verbais da criança.

\section{A trajetória de produção de dados}

Participaram da pesquisa duas professoras, seis Auxiliares de Desenvolvimento Infantil (ADI) e 31 crianças de ambos os sexos, com idades entre oito e 16 meses, integrantes de dois Centros Municipais de Educação Infantil (CMEI) da cidade do Recife-PE, pertencentes ao agrupamento etário denominado de berçário. As crianças foram observadas nas suas próprias salas de convivência, com a presença de professoras e Auxiliares de Desenvolvimento Infantil.

As observações foram videogravadas e ocorreram em quatro momentos da jornada diária da instituição, a saber: a) momentos de ações dirigidas às crianças pelo adulto profissional; b) ocasiões de atividades de livre escolha pela criança; c) durante $o$ 
almoço; e d) no horário do repouso, após o almoço. Foram realizadas 38 sessões de filmagem, perfazendo um total de 19 horas de observação, realizadas durante um período de três meses. Os dados foram tratados por meio da análise microgenética, em que cada sessão foi observada atentamente a fim de serem recortados episódios interacionais orientados por dois conjuntos de indicações: a) engajamento social entre crianças; e b) engajamento de crianças com adultos profissionais nas práticas cotidianas do berçário.

Considerando o objetivo deste estudo, buscamos a videogravação como recurso metodológico para apreender as sutilezas do comportamento interativo das crianças com seus pares, visando a um detalhamento a partir da contemplação e da repetição sistemática do observado, na perspectiva de alcançar posturas argumentativas advindas desse exercício de compreender o fenômeno-alvo de análise (PEDROSA; CARVALHO, 2005).

As videogravações focavam preferencialmente a díade criança-educadora ou o grupo de crianças com a educadora, quando existiram sinais conspícuos de interação por período de tempo compatível com a possibilidade de investigar esse processo. Outros momentos do registro foram definidos pela presença de duas ou mais crianças envolvidas numa sequência interacional. Tal organização social foi percorrida pelas tomadas em grupos, cujo registro seguia pistas de proximidade espacial e de orientação da criança e prosseguia até o término da atividade em que as crianças estivessem socialmente engajadas.

Ressaltamos que em vários momentos dos registros a imagem foi aproximada através do zoom, objetivando obter mais detalhes sobre a atividade das crianças. A decisão de interromper o registro era definida pela pesquisadora que avaliava se aquele segmento de registro seria profícuo ou não para o objetivo pretendido.

No percurso de produção de dados, cada registro videogravado foi assistido pelo menos duas vezes, ocasião em que se podia circunscrever as ações entre parceiros envolvidos em brincadeiras ou outras atividades partilhadas.

A configuração interacional recortada foi denominada de episódio (PEDROSA; CARVALHO, 2005). O percurso de exploração de cada episódio videogravado foi feito mediante a observação e descrição das ações interativas das crianças. As cenas foram vistas, ora em velocidade normal, ora acelerada, noutras vezes com a imagem "congelada" momentaneamente ou voltando às imagens que pareciam conter detalhes reveladores de informações pertinentes ao campo investigado.

Nessa ocasião, uma pergunta guiou o percurso investigativo: como as crianças iniciam o contato social com o parceiro e se entrosam em atividades propostas pela professora e/ou pela ADI? Em seguida, buscamos examinar e descrever aspectos qualitativos dos episódios com o olhar centrado nas interações das crianças com o coetâneo e com os adultos profissionais, explorando as formas de inserção da criança na atividade proposta pelo adulto; a sequência da experiência interativa; o tipo de atividade em que os parceiros estavam envolvidos; o tipo de proposta sugerida pela educadora; o modo de implementação da proposta; a participação das crianças na proposta, examinando situações geradas a partir das sugestões da professora e/ou da ADI; o modo como o adulto interage com as crianças durante o desenrolar da atividade; o uso de recursos materiais e da organização do espaço físico, bem como o modo como as crianças se organizam socialmente com os materiais disponíveis na sala.

Uma vez efetuada a transcrição das situações interativas eleitas, decidiu-se percorrer as singularidades de cada episódio agrupando detalhes pertinentes à organização interacional construída pelo grupo ou díades. Para tal empreendimento, foram utilizados códigos a fim de identificar eventos comuns por meio de cores e sinais gráficos.

Uma vez efetuada essa codificação, o próximo passo foi comparar as distintas circunstâncias no intuito de apreender as especificidades dos dados através do confronto entre diferenças, traços comuns ou elementos recorrentes alçados das situações interativas observadas.

Para a apresentação dos resultados do presente estudo, julgamos pertinente resumir os momentos dos episódios escolhidos, preservando detalhes que orientassem o leitor para os aspectos da discussão que se pretendeu realçar em cada trama interacional que foi selecionada e intitulada, e que serão apresentadas a seguir. 


\section{Ouvindo a criança e enxergando possibilidades de participação dos bebês na organização curricular}

Os dados apresentados nessa secção se coadunam com a recente consideração de que as crianças têm uma voz própria e devem ser ouvidas na tomada de decisões democráticas (DELGADO; MÜLLER, 2005; GRAUE; WALSH, 2003; MOSS, 2005), esboçando possibilidades para se (re)pensar o processo educacional e o papel dos profissionais que organizam as práticas de Educação Infantil em sintonia com esse status de participação social que recentemente a criança conquistou, conforme já apresentamos.

Realçamos a ideia de que esse modo de pensar a ação pedagógica aponta vias de acesso para a criança, desde bebê, ter um espaço de participação no fazer pedagógico baseada num processo dialógico de escuta e de negociações entre a intencionalidade conhecida para o ato educativo e a sua codefinição pelos sujeitos aprendizes (MONTANDON, 2005; OLIVEIRA-FORMOSINHO; KISHIMOTO; PINAZZA, 2007).

$\mathrm{O}$ foco reside em abordagens que confluam para a perspectiva da criança como sujeito social, constituído prioritariamente na e pela interação social. Assim, o ponto central se torna refletir sobre a potência da produção e compartilhamento de significados por meio de múltiplas linguagens que as crianças produzem (EDWARDS; GANDINI; FORMAN, 1999).

Abrimos, então, a discussão sobre o papel do(a) professor(a) de inserir o bebê numa posição de informante ao se dirigir a ele pelo viés da escuta de suas possibilidades expressivas não verbais, interesses, necessidades.

Nessa trilha de proposições, escolhemos o episódio "Quer tomar banho agora?" para iniciar o debate. Inicialmente cabe pontuar que a situação interativa a ser apresentada aconteceu num horário próximo ao almoço, ocasião em que, diariamente, as crianças tomam banho. Conforme observamos, há uma característica que circunscreve fortemente os eventos interativos do episódio: a consulta à criança quanto à possibilidade de tomar banho no momento solicitado, através dos insistentes contatos verbais da professora dirigidos ao grupo de bebês. Isso pode ser demonstrado nos diferentes momentos em que ela fala com várias crianças da sala, enfatizando seu aparente desejo de consultá-las.

A professora sai do fraldário e olha para os diversos ângulos da sala, como se estivesse rastreando o ambiente, quando pergunta: 'Quem quer vir tomar banho agora?' [pausa]. 'Quem quer vir?' [pausa]. 'Quem quer vir tomar banho agora?' [pausa]. 'Quem quer vir?' [pausa]. 'Quem, heim?' Em seguida, já próxima ao grupo de bebês que estavam nos colchonetes no chão, ela retoma o convite, saltitando e falando num tom de canção: 'Quem quer tomar banho?' [pausa]. 'Tomar banho...' [pausa]. 'Um banho...' As crianças continuam envolvidas em suas ações. Ela repete duas vezes a pergunta, falando mais alto que das vezes anteriores, usando um tom que parece se aproximar mais de uma afirmação do que uma consulta: 'Quem vai tomar banho agora, heim?!' [pausa]. 'Quem vai tomar banho agora?' [pausa]. Ela olha para Jade (12 meses) e lhe pergunta: 'É Jade?' A garota interrompe a manipulação de pecinhas, olha em sua direção e sai engatinhando. Em seguida, a professora olha para Gabriel (14 meses) e diz: 'Gabriel?' [pausa]. Ele balança a cabeça para lá e para cá, como se falasse 'não'. A professora olha para Ayana (14 meses) e lhe fala num tom de convite: 'Ayana' [pausa], 'tomar banho!' A garota para de mexer na boneca que segura, levanta a cabeça na direção do adulto; em seguida, olha para uma ADI quando esta lhe diz: 'Diga: eu tô brincando agora!' [pausa]. A professora desvia o olhar de Ayana e olha na direção do grupo, perguntando para as outras crianças: 'Quem vai tomar banho agora?' [pausa]. 'Quem quer?' Olha outra vez para Ayana e lhe pergunta: 'Quer, Ayana, tomar banho logo?'A garota lhe responde alto e veementemente: 'Não!' A professora diz para ela: ‘Quer não, é?’ Ayana balança a cabeça para lá e para cá, como se dissesse 'não'. A professora convida Gabriel Prado (11 meses), dizendo: 'Vem, Gabriel!' Ele olha para ela e lhe diz 'não' de um jeito prolongado. Malu (11 meses) se aproxima engatinhando, levanta e estica os braços na direção da professora, olhando para ela. Ela sorri, segura nas mãos da garota, a levanta e em seguida a conduz ao fraldário, dizendo num tom de aparente satisfação: 'Bora tomar banho!'

Como se faz notar no fluxo de eventos, chama atenção o fato de a professora não interromper de modo imperativo, mas consultivo, as atividades das crianças no horário destinado ao banho. Ao 
perguntar diversas vezes "Quem vai tomar banho agora?”, ela parece esperar a resposta de um possível interlocutor diante de suas insistentes consultas. Isso pode ser demonstrado em suas ações: a) ela não retira logo a criança da sala para o banho no fraldário, mesmo estando num horário da jornada educativa definido para isso; b) escaneia com o seu olhar a sala em várias direções, como se estivesse a procura de alguém disponível para se banhar; e c) atribui aos gestos de Malu uma aceitação ao convite ao vê-la engatinhar e esticar o braço em sua direção. Ela segura nas mãos da garota, conduzindo-a para o fraldário e lhe dizendo "Bora tomar banho!".

Dessa forma, torna-se possível perceber uma "inversão" de posicionamento dos adultos frente às crianças, ao considerar não o que lhes falta, como a presença da fala articulada, mas reconhecendo suas potencialidades para interagir com as pessoas e com os eventos sociais que ocorrem, a exemplo da escolha na vez de tomar banho. Em suas ações, os bebês demonstram que aproveitaram a situação interativa para expressar ativamente seus interesses e posicionamentos através de diferentes manifestações sociocomunicativas.

A partir desse episódio, torna-se possível pensar que uma atmosfera comunicativa que insira o bebê no universo discursivo que é próprio da língua materna pôde ser instaurada na sala quando a professora se dirigiu verbalmente à criança, inserindo-a numa posição de informante, reconhecendo-a enquanto sujeito socialmente competente e, dessa forma, abrindo perspectivas para ela assumir uma postura de interlocução ativa.

O próximo episódio, denominado "Qual é a música?”, permite ampliar essa discussão. Trata-se de mais uma situação interativa em que a criança ganha possibilidades de participar da organização de ações a serem dirigidas ao grupo infantil. No contínuo interacional, os sinais expressivos de um bebê são deflagradores da continuação da proposta educativa iniciada pela professora, conforme apresentaremos.

Aína (11 meses) passeia pela sala balançando um brinquedo e pronunciando sílabas com melodia. A professora e a ADI que estão cantando e dançando com as crianças, olham para a garota e sorriem. A professora pergunta: 'Tu tá cantando o quê, Aína?' A ADI olha para a professora e lhe responde: 'Ela tá tentando cantar alguma música...'. Aína se aproxima, olha para a professora e continua vocalizando. A professora olha para a garota e outra vez lhe interroga: 'Aína, qual é a música?' [pausa]. Em seguida, a professora fala num tom de descoberta: 'Já sei!', e começa a cantar a música Atirei o pau no gato, batendo palmas e chamando as outras crianças para cantar e bater palmas também.

Como se faz notar, as ações de Aína são inseridas na organização didática quando a professora observa e atribui diferentes sentidos às possibilidades expressivas que a garota comunica em suas vocalizações. Isso pode ser notado quando a professora interrompe a atividade com o grupo de crianças e se dirige verbalmente a Aína, mostrando-se regulada por seus sinais sonoros. Ao perguntar para a garota: “Tu tá cantando o quê, Aína?”, a professora atribui aos balbucios da criança o significado de canção, talvez admitindo ser uma extensão da atividade de cantar que está sendo realizada na sala. Vale apontar que a possibilidade de as vocalizações de Aína serem portadoras de uma canção também é respaldada pela opinião da ADI, quando fala para a professora "Ela tá tentando cantar alguma música...".

Dessa forma, ao perguntar para Aína "Qual é a música?" e atribuir significados aos balbucios da garota, a professora gerou possibilidades de a criança participar da atividade como informante da canção a ser executada junto ao grupo. Isso também pode ser demonstrado nas ações da professora quando fala "Já sei!" (referindo-se à descoberta da possível música entoada por Aína) e começa a cantar a música Atirei o pau no gato, batendo palmas e chamando as outras crianças para cantarem e baterem palmas também.

Sendo assim, na trama de interações vividas, as vocalizações de Aína, possivelmente uma imitação de seus parceiros que cantavam (ou arremedavam a professora), ganham status de informação portadora de uma canção: professora e ADI interpretam os balbucios da criança como trechos da música Atirei o pau no gato e, posteriormente, inserem os balbucios nas atividades dirigidas para o grupo de crianças.

Esses elementos nos permitem dizer que Aína foi incluída na organização de ações dirigidas ao grupo infantil quando os adultos profissionais 
mostraram-se atentos às suas manifestações comunicativas, ressignificando os balbucios e as vocalizações da garota, procurando compreendê-los, completá-los e interpretá-los.

Dando continuidade à discussão e pautados nas observações da dinâmica interativa do próximo episódio a ser apresentado, as expressões sociocomunicativas dos bebês foram sendo acolhidas e interpretadas pelo outro bebê e pela professora, oferecendo-nos pistas do quanto as crianças, desde bem novas, são atentas e responsivas às ações e às reações do outro, realçando a ideia de que não são passivas na relação social. Ao contrário, participam de diálogos não verbais, apreendendo informações e elaborando diferentes respostas para as manifestações do parceiro para consigo, desde bebês. No desenrolar do episódio intitulado "Balanços", a professora mostrou-se atenta e intérprete dos sinais comunicativos das crianças, compondo com o grupo infantil um repertório de informações que permitiu a ordem de entrada de cada uma na brincadeira proposta.

A professora convida o grupo de bebês para a brincadeira: 'Quem vai querer brincar de serra-serra?' Mara (12 meses) estende seus braços na direção da professora em resposta à pergunta deste adulto, ocasião em que a professora olha para ela e interpreta os seus gestos como sendo adesão ao convite que foi feito, puxando e levantando a garota para brincar. Ela comunica que gostou de brincar através de seus gestos e movimentos nas duas vezes em que a brincadeira foi interrompida: não solta as mãos da professora e joga-se para trás com suas pernas estiradas, olhando para a professora quando ela para de balançá-la. Isso sinalizou para a professora um desejo da garota permanecer brincando que ela consolida em suas ações: fala "De novo!” e reinicia a brincadeira com Mara. Mara repete a mesma estratégia de outrora, quando os balanços do corpo são interrompidos pelo término da brincadeira: não solta as mãos da professora, estica-se para trás com suas pernas estiradas e, assim, comunica seu interesse em permanecer brincando. A professora recomeça a brincadeira, evidenciando atribuição de significados aos sinais expressivos que a garota comunicou. Karli (14 meses) parece demonstrar interesse em participar da brincadeira por meios diferentes daqueles usados por Mara: aproxima-se, olha para a professora, aponta para a brincadeira que está acontecendo, pega na mão de Mara, que está se balançando de mãos dadas com a professora, acompanha com a cabeça o movimento de Mara se balançar para frente e para trás, depois alterna o olhar para a professora e para Mara enquanto balança devagarzinho seu corpo para frente e para trás, como se imitasse os movimentos cadenciados da brincadeira, e choraminga quando a professora recomeça a balançar Mara. A professora não permanece alheia a essa configuração de ações, possivelmente por interpretá-las como sendo pedidos para participar da brincadeira. E, diante disso, interrompe a brincadeira com Mara e fala para ela: 'Agora é Karli!', e começa a balançar Karli para frente e para trás, evidenciando a partilha de intenções com a criança. Luiz (13 meses) também parece interessado em participar da brincadeira, tanto que se aproxima e tenta segurar nas mãos da professora que está balançando Karli. A proximidade de Luiz e o gesto de segurar nas mãos da professora provocam um contato verbal: 'Já, já, viu, Luiz!', sinalizador do vínculo e da informação portadora das intenções de ingresso na brincadeira que a professora efetiva em suas ações. Conclui a brincadeira com Karli e fala: 'Agora é Luiz!', comunicando ao garoto as intenções apreendidas dos seus movimentos. Igor (11 meses) não se locomove com a mesma desenvoltura que os seus parceiros, mas sinaliza interesse na atividade de balanços entre Luiz e a professora quando engatinha na direção da dupla que brinca, segura nas costas da professora para se erguer e se aproximar dos parceiros. Esses movimentos do garoto deflagram sua entrada na brincadeira, pelas intenções da professora assumidas verbalmente ('Agora é Igor!') e gestos que executa (traz o garoto pra frente de seu corpo, segura em suas mãos e começa a balançá-lo para frente e para trás).

Como se faz notar nas ações e reações das crianças, os seus sinais comunicativos foram emergindo a partir da atenção dirigida ao outro e sustentados por recursos corporais. Dessa forma, através da dimensão corporal, a criança teve a chance de compartilhar significados em práticas pedagógicas que lhes foram dirigidas e por meio das quais ela pôde expressar suas disposições emocionais e cognitivas em resposta às pistas fisionômicas, posturais e entonacionais, e outros sinais comunicativos advindos da professora, que os capturou e interpretou, conforme observamos nas (re)ações dos bebês que participaram da experiência apresentada. 
Ao observar o comportamento interativo dos bebês integrantes dos episódios apresentados, percebemos que o modo dos meninos e meninas se relacionarem com os eventos pedagógicos que lhes foram apresentados foi ativo, em movimento de ser e estar, assim, construíam suas relações interativas com e através de seu corpo. Os diálogos não verbais foram sustentados por recursos corporificados, compreendendo que a comunicação é um processo dotado de múltiplos canais, incluindo a gestualidade, a mímica, as posturas, a língua, os silêncios, a tonalidade da voz (LE BRETON, 2009), dentre outros.

Cabe destacar que o diálogo sem palavras, qual seja, via linguagem corporal, se efetivou à medida que os gestos da criança ganharam um status de portadores de significados através da interpretação e atribuição de sentidos que lhes foram impregnados pelo parceiro social, permitindo a emergência e os compartilhamentos. É nesse sentido que o corpo expressa, por meio de suas posturas, gestos e ações, as significações construídas.

É nessa linha de argumentação que destacamos as possibilidades expressivas não verbais como forma de "linguagem sensório-motora" em crianças pequenas que ainda não falam. Essa suposição está, portanto, apoiada nos pressupostos wallonianos que balizam a concepção de que os elementos iniciais de significação emergem na experiência corporal através das emoções, das sensações, dos gestos e dos movimentos. Apoiados em Wallon (1971), podemos dizer que os processos de construção de significados se efetivam no uso e no sentido do comportamento, logo a ação motora assume a função de expressar as disposições íntimas da criança, ou seja, seus interesses e motivações.

Numa outra esfera de argumentação, os dados apresentados no próximo episódio - "Jeito de dormir" - sinalizam perspectivas para o adulto profissional olhar, ouvir e conhecer as crianças do grupo pelas quais é responsável, de forma respeitosa ao que é específico de cada bebê, percebendo-os e valorizando-os como plurais.

Da longa sequência interativa videogravada, que possui 19 minutos e 03 segundos, os seis momentos recortados nos revelam diferentes formas e posições corporais que as crianças encontram para relaxar e dormir, mediadas pelas atitudes delicadas e cuidadosas das ADI e da professora.
Uma ADI senta no colchonete, segura e balança Pedro (10 meses) apoiado nas suas pernas, olhando para ele. Em alguns momentos, ela interrompe o balançado para alisar o rosto da criança. [...] Pedro abre e fecha os olhos como se estivesse quase adormecendo. Ela aproxima o garoto para perto do seu colo e começa a alisar as pernas dele, que fecha os olhos e dorme. Gabriel (14 meses) deita no colchonete com o bumbum para cima. A professora se aproxima, senta ao lado do garoto e começa a balançar suavemente a fralda da criança para lá e para cá. Depois alisa a cabeça do garoto e volta a niná-lo, desta vez dando umas pancadinhas bem leves no bumbum de Gabriel até ele dormir. Alice (13 meses) aparece no foco sentada nas pernas de outra ADI, com a sua cabeça apoiada no colo do adulto e com as pernas abertas na cintura da educadora. A ADI se balança para frente e para trás, sentada na cadeira de amamentar, movimentando o corpo da criança junto com o seu. Em alguns momentos, a ADI interrompe os balanços do corpo, apoia e desliza as duas mãos nas costas de Alice, massageando suavemente toda a extensão abaixo do pescoço até o bumbum da criança. Em seguida, junta os dedos das mãos e dá umas batidinhas suaves, percorrendo toda a região das costas da garota. Outra ADI coloca Malu (11 meses) nos seus braços. A garota apoia o rosto no colo do adulto, que se desloca pela sala, balançando-a. Em alguns momentos, a ADI para, substitui os balanços por giros do corpo, olhando para Malu. [...] Esta levanta a cabeça; a ADI, então, recomeça a andar pela sala, balançando-se, até Malu voltar a deitar o rosto no seu colo e dormir. A câmera foca uma ADI sentada no colchonete com Fernando (14 meses), que está sentado com as pernas abertas na cintura do adulto e com a cabeça apoiada no seu colo. Delicadamente, a ADI segura e levanta um punhado de fios do cabelo do parceiro por repetidas vezes, depois desliza suas mãos suavemente por toda a extensão da cabeça da criança, afagando seus cabelos até ela adormecer. Ayana (14 meses) pega uma boneca de pano e se deita no colchonete com o tórax para cima, segurando o brinquedo. Em seguida, solta a boneca, vira-se no colchão com os olhos fechados e posiciona seu rosto em cima da boneca. A ADI dirige-se até ela, tira a boneca de debaixo da cabeça de Ayana, emborca a garota no colchonete e coloca o brinquedo embaixo de uma das mãos da criança.

Os dados apresentados no episódio sinalizam perspectivas para o adulto profissional, em suas 
práticas cotidianas, aprender a auscultar os ritmos biológicos de cada criança e as suas cadências rítmicas e afetivas de forma a não se deixar conduzir pela voracidade de uma jornada diária que automatiza ações e homogeneíza as crianças (BARBOSA, 2006).

Refletindo-se dessa maneira, minimiza-se o risco de ofuscamento das motivações das crianças e se substituem práticas adultocentradas por outras que estejam mais ajustadas ao interesse e às possibilidades das crianças.

Os achados reforçam, portanto, resultados de outros estudos que tecem críticas ao modelo de educação, no qual todas as crianças devem seguir os mesmos tempos, os mesmos modos, seguindo a lógica do consenso que abafa a pluralidade e sufoca a diferença (BARBOSA, 2006; MARTINS FILHO, 2005; MARTINS FILHO et al, 2006).

Nesse sentido, Post e Hohmann (2004, p. 201) defendem que para o/a professor(a) organizar uma rotina pensada para crianças pequenas, é preciso que ele "veja o dia através dos olhos das crianças", pois só assim ele estará preparado para atender as suas verdadeiras necessidades.

Como apontam Carvalho, Muller e Sampaio (2009), concordamos que os profissionais da Educação Infantil estão sendo convidados para investir na organização de espaços e tempos para a criança pôr em execução, na unidade educacional, suas características, motivações intrínsecas e especificidades de suas infâncias. Avançando no diálogo com essas autoras, reconhecemos que essa discussão coopera no sentido de enxergar o percurso singular e criativo que a criança empreende no mundo, em profunda interlocução com as histórias das pessoas, dos contextos nas quais convive e em sintonia com o papel educativo da creche, respeitoso às especificidades que os bebês comunicam.

\section{Apontamentos conclusivos}

Olhar para o bebê no contexto da Educação Infantil e ouvi-lo em seus interesses viabilizaram a captura e a compreensão de seu ponto de vista como elemento que balizou a construção de um trabalho pedagógico a partir das competências que seu comportamento interativo pôde desvelar, conforme apresentamos.
Quando demonstram suas atitudes interativas e de acolhimento às manifestações infantis, as educadoras participantes deste estudo indicam como é possível favorecer as aquisições sociocomunicativas do bebê, reconhecendo-o enquanto sujeito socialmente competente e capaz de organizar suas percepções e expressá-las criativamente, atribuindo diferentes sentidos ou, quem sabe, elaborando novos significados àqueles propostos pelo interlocutor.

Nessa trilha de proposições, oferecer a ajuda necessária para o desenvolvimento das ideias da criança, apoiá-las na interpretação de suas ações, na ressignificação de seus atos, podem ser consideradas ações importantes num ambiente pedagógico que considera e impulsiona o modo próprio de agir, de pensar e de sentir do bebê.

Nessa esfera de atuação profissional, os atos pedagógicos puderam produzir significados em sintonia com o grupo infantil, de forma que os adultos profissionais também conseguiram extrair sentido da prática que estava sendo proporcionada à criança.

Tal movimento investigativo viabilizou que as professoras também pudessem consolidar-se como produtoras de significados, criando instrumentos de recolha de descobertas que promoveram propostas e situações desafiadoras para os bebês, nas quais foi incluída a possibilidade de exploração de materiais e espaços, de encontro com outras pessoas, crianças e adultos, tendo como foco as escolhas e as predileções de cada uma.

Ampliando o debate, acreditamos que essa parceria assumida com a criança abre espaço para a efetivação da finalidade da Educação Infantil, qual seja, o desenvolvimento pleno e integrado da criança desde o comecinho da vida (BRASIL, 2009). Permite que o/a professor(a) (re)visite sua prática, reconheça-se noutras, enxergue avanços e desafios a serem construídos com seus pares, a depender da efetivação de ações desenvolvidas no interior das práticas cotidianas da Educação Infantil por cada um(a) deles(as). Estamos falando da possibilidade de o adulto profissional poder caminhar de mãos dadas com o bebê, percorrendo suas tramas, apoiando suas iniciativas, curiosidade investigativa, interesses, singularidades e potencialidades sociocomunicativas. 
Nos rumos de efetivação de tais ideias, as crianças ganham a oportunidade de impor, se assim desejarem, o reverso de uma lógica adultocêntrica instituída pelos adultos profissionais; suas ações podem traçar outros contornos para o cotidiano pedagógico que foi planejado; suas travessuras e curiosidade investigativa preenchem o berçário da creche de alegria e movimento, convidando-nos a construir o ambiente da Educação Infantil como um espaço de seu pertencimento com toda sua ludicidade, originalidade, inventividade, criatividade, encantamento.

O foco da organização didática recai, portanto, em abordagens que confluam para a perspectiva de refletir-se sobre a potência da produção e compartilhamento de significados por meio de múltiplas linguagens que os bebês produzem.
Desse modo, o acesso às múltiplas formas de expressão, explorações, oportunidades de interações e uso ativo de recursos que o bebê emprega para se comunicar, agir e significar pode revelar valiosos aspectos sobre suas potencialidades e trazer informações necessárias para a configuração de práticas educativas construídas com as crianças e para elas.

Com base nesse olhar, fortalecemos a concepção de educação centrada na criança que vem sendo pensada: aquela que enxerga e acolhe o protagonismo social do bebê e que busca aprender com as crianças, conhecer seus gestos, ouvir suas falas, compreender suas interações como bússolas a indicar caminhos e traçar rotas a serem navegadas pela Educação Infantil. Já é chegada a hora de levantar a âncora e partir. Navegar é preciso...

\section{REFERÊNCIAS}

ADES, César. Um adulto atípico na cultura das crianças. In: MULLER, Fernanda; CARVALHO, Ana Maria Almeida. Teoria e prática na pesquisa com crianças. São Paulo: Cortez, 2009. p. 127-136.

BARBOSA, Maria Carmen Silveira. Por amor e por força - rotinas na educação infantil. Porto Alegre: Artmed, 2006.

BRASIL. Conselho Nacional de Educação. Câmara de Educação Básica. Parecer CNE/CEB nº 20/2009. Diretrizes Curriculares Nacionais para Educação Infantil. Brasília, DF: 2009.

CAMAIONI, L. L'Interazione tra bambini. Roma: Armando, 1980.

CAMPOS, Maria Malta. Por que é importante ouvir a criança? A participação das crianças pequenas na pesquisa científica. In: CRUZ, Sílvia Helena Viera (Org.). A criança fala: a escuta da criança em pesquisas. São Paulo: Cortez, 2008. p. 127-139.

CARVALHO, Ana Maria Almeida; BERALDO, K. E. A. Interação criança-criança: o ressurgimento de uma área de pesquisa e suas perspectivas. Cadernos de Pesquisa, São Paulo, n. 71, p. 55-61, nov. 1989.

CARVALHO, Ana Maria Almeida; MULLER, Fernanda; SAMPAIO, Sonia Maria Rocha. Sociologia da infância, psicologia do desenvolvimento e educação infantil: diálogos necessários. In: MULLER, Fernanda; CARVALHO, Ana Maria Almeida (Org.). Teoria e prática na pesquisa com crianças. São Paulo: Cortez, 2009. p. 189-204.

COHN, Clarice. Antropologia da criança. São Paulo: Zahar, 2005.

CORSARO, Willian. The sociology of childhood. London: Pine Forge Press, 2005.

CRUZ, Sílvia Helena Vieira (Org.). A criança fala: a escuta de crianças em pesquisas. São Paulo: Cortez, 2008.

DELGADO, Ana Cristina Coll; MÜLLER, Fernanda. Sociologia da infância: pesquisa com crianças. Educação \& Sociedade, Campinas, SP, v. 26, n. 91, p. 351-360, maio/ago. 2005.

EDWARDS, Carolyn; GANDINI, Lella; FORMAN, George. As cem linguagens da criança. Porto Alegre: Artes Médicas, 1999.

FARIA, Ana Lúcia Goulart de. O espaço físico como um dos elementos fundamentais para uma pedagogia da Educação Infantil. In: GOULART, Ana Lúcia de Faria; PALHARES, Marina Silveira (Org.). Educação infantil pós-LDB: rumos e desafios. Campinas, SP: Autores Associados, 2007. p. 37-41.

GRAUE, Elisabeth; WALSH, Daniel. Investigação etnográfica com crianças: teorias, métodos e ética. Lisboa: Fundação Calouste Gulbenkian, 2003. 
HORN, Maria da Graça Souza. Sabores, cores, sons, aromas: a organização dos espaços na educação infantil. Porto Alegre: Artmed, 2004.

JABLON, Judy; DOMBRO Amy Laura; DICHTELMILLER, Margo. O poder da observação. Porto Alegre: Artmed, 2009.

KRAMER, Sônia. Infância, cultura contemporânea e educação contra a barbárie. In: BASÍLIO, Luís Carlos C.; KRAMER, Sônia. Infância, educação e direitos humanos. São Paulo: Cortez, 2003. p. 85-98.

KUHLMANN JUNIOR, Moysés. Educação infantil e currículo. In: GOULART, Ana Lúcia de Faria; PALHARES, Marina Silveira (Org). Educação infantil pós LDB: rumos e desafios. Campinas, SP: Autores Associados, 2007. p. 21-36.

LE BRETON, David. A sociologia do corpo. Petrópolis, RJ: Vozes, 2009.

MONTANDON, Cléoâtre. As práticas educativas e a experiência das crianças. Educação \& Sociedade, Campinas, SP, v. 26, n. 91, p. 143-162, maio/ago. 2005.

MARTINS FILHO, Altino José (Org.). Criança pede respeito. Porto Alegre: Mediação, 2005.

MARTINS FILHO, Altino José. Et al. Infância plural: crianças do nosso tempo. Porto Alegre: Mediação, 2006.

MOSS, Peter. Recontextualizando a infância: crianças, instituições e profissionais. In: MACHADO, Maria Lucia de A. Encontros e desencontros em educação infantil. São Paulo: Cortez, 2005. p. 124-138.

OLIVEIRA-FORMOSINHO, Júlia; KISHIMOTO, T. M.; PINAZZA, M. A. (Org.). Pedagogia(s) da infância: dialogando com o passado, construindo o futuro. Porto Alegre: Artmed, 2007.

PEDROSA, Maria Isabel; CARVALHO, Ana Maria Almeida. Análise qualitativa de episódios de interação: uma reflexão sobre procedimentos e formas de uso. Psicologia, Reflexão e Crítica, Porto Alegre, v. 18, n. 3, p. 431442, 2005.

PIMENTA, Selma Garrido. Saberes pedagógicos e atividade docente. São Paulo: Cortez, 1999.

POST, Jacalyn; HOHMANN, Mary. Educação de bebés em infantários - cuidados e primeiras aprendizagens. Lisboa: Fundação Calouste Gulbenkian, 2003.

RAMOS, Tacyana Karla Gomes Ramos. A criança em interação social no berçário da creche e suas interfaces com a organização do ambiente pedagógico. 2010. 178 f. Tese (Doutorado em Educação) - Universidade Federal de Pernambuco (UFPE), Recife, 2010.

RIBEIRO, Fernando Luiz; BUSSAB, Vera Sílvia Raad; OTTA, Ema. De colo em colo de berço em berço. In: MOURA, Maria Lucia Seill de (Org.). O bebê do século XXI e a psicologia em desenvolvimento. São Paulo: Casa do Psicólogo, 2004. p. 230-284.

ROCHA, Eloisa Acires Candal. Por que ouvir as crianças? Algumas questões para o debate científico interdisciplinar. In: CRUZ, Sílvia Helena Viera Cruz (Org.). A criança fala: a escuta da criança em pesquisas. São Paulo: Cortez, 2008. p. 43-51.

SARMENTO, Manuel Jacinto. Sociologia da infância: correntes e confluências. In: SARMENTO, Manuel Jacinto; GOUVEA, Maria Cristina Soares de (Org.). Estudos da infância. Petrópolis, RJ: Vozes, 2008. p. 73-85.

SOUZA, Gisele (Org.). Criança em perspectiva: olhares do mundo sobre o tempo infância. São Paulo: Cortez, 2007.

TARDIF, Maurice. Saberes docentes e formação profissional. Rio de Janeiro: Vozes, 2002.

TRISTÃO, Fernanda Carolina Dias. Ser professora de bebês: um estudo de caso em uma creche conveniada. 2004. 213 f. Dissertação (Mestrado em Educação) - Centro de Ciências da Educação, Universidade Federal de Santa Catarina (UFSC), Florianópolis, 2004.

WALLON, Henri. A expressão das emoções e seus fins sociais. In: . As origens do caráter na criança: os prelúdios do sentimento de personalidade. São Paulo: Difusão Europeia do Livro, 1971. p. 89-94. 